\title{
The Study about Incremental Cost of Green Building Based on Life- cycle Theory
}

\author{
${ }^{a}$ H.L. LI\& S.H. LIU \& M.Y. LI, ${ }^{b} H . Z H U$ \\ aSchool of Management, Shenyang jianzhu University, Shenyang , Liaoning , China \\ ${ }^{b}$ Supervision Company, Shenyang jianzhu University, Shenyang, Liaoning , China
}

\begin{abstract}
KEYWORD: Green building;Full life cycle;Incremental cost
ABSTRACT: A comprehensive analysis framework of the study of green building incremental cost will be given in this paper, from the perspective of the whole life cycle,we will discuss the concept and characteristics of incremental cost,providing it with overall process, whole stage and a full range of recognition and quantitative based on an overall analysis of its factors, then build a framework for its cost of whole life cycle which will provide important theoretical and practical significance to the study of development of green building.
\end{abstract}

\section{INTRODUCTION}

Green building refers to the architectures that can accomplish maximum resource saving,protect environment from pollution,provide healthy,applicab le and effective space to people and achieve Harmonious coexistence with nature [1]. With in-depth study and practice in promoting green building, technology of green buildings, evaluating systems and managing regulations are gradually improved. But they still have a small proportion compared to the overall building area, restricted by many factors in the process of development, so the development remains slowly. Incremental cost of green building is an important restriction factor in the process of the development of green building in our country,so a correctly and reasonable research is in need,which is very important for the large-scale promotion of the healthy development of the green building.

\section{AN OVERVIEW OF GREEN BUILDING INCREMENTAL COST}

\section{The concept of green building cost}

In green buildings' designing specification(draft),gre

en building incremental cost is defined as:

construction projects designed according to the "green building evaluation standard" GB/T503782006 and aiming at star green building [2], and the values that added into the cost in the process of project implementing, can be positive or negative.

In short, the incremental cost refers to incremental investment when try to achieve the goals of green buildings by using green building techniques which are different from that of benchmark buildings, it is the difference between the two.

\section{Characteristics of green building cost increment}

(1) The systematicness

All the parts of incremental cost are interconnect,just as green building incremental cost in every stages of whole life cycle,manifests the systematicness of the incremental cost, each part is closely linked, inseparable.

(2) The life cyclical

Green building itself demonstrate a kind of periodicity of whole life, green building incremental cost occurred in every stage, including the design of

Decision-making, construction, operation and maint

Enance,demolition of the whole process,the omni-directional incremental cost.

(3) The gray 
The gray of incremental cost means that in the process of incremental cost recognition and quantitative, we should not consider the internal, dominant and quantifiable incremental cost, external and the cost which is difficult to quantify can't be ignored, make external costs internal when calculating as far as possible, and consider certain risks.

(4) The rate of incremental cost is reducing year by year

In recent years,with rapid development and promotion of green buildings, the market supply, technology selection, cost control demonstrate a trend of increasingly mature from the level of designing knowledge, the incremental cost rate is reducing year by year.

\section{FACTORS THAT AFFECT THE GREEN BUILDING INCREMENTAL COST OF WHOLE LIFE CYCLE}

\section{The effects on incremental cost of main technical measures}

Compared with the benchmark of traditional architecture, green building aims to realize the goal of green building and green function, which means that various technical measures are in need, and the cost will inevitably increase. According to reports of a research institution, among the six main technical measures, green building incremental cost mainly comes from the requirement of the "energy saving and energy use", building energy efficiency technology determines the green buildings' incremental cost to a certain extent. Then comes the cost of operation management and interior environmental, finally are the technical measures for water, land and materials saving.

\section{The project positioning impact on}

(1) Project concept

Incremental cost are influenced by different positioning concept of green building. In generally, the construction project positioning concept can be divided into the three types, paying attention to reaching standards, concentrating on efficiency and pursuing leading types.Based on data analysis from the survey, the average increment cost of paying attention to reach standards type of green building is the lowest, the one concentrating on efficiency ranks second,then the pursuing leading type has the highest percentage of average increment cost.

(2) The star standards

Our star evaluation standards include $\star 、 \star \star$ and $\star \star \star \star$ according to "The green building star evaluation criteria"in China. As a whole,the higher the green building star-level is, the higher is the incremental cost. It is mainly because if the projects are evaluated by different star standards, it will faced with different project evaluation requirements which will result in the differences of incremental cost .

\section{Effect of the green building feasibility researching time on incremental cost}

The feasibility study on green building in different stages will also influence the incremental cost directly[3]. The earlier it begins in the process of decision-making,the more possibilities we have when fully consider various influencing factors of the project, optimizing the design, using advanced green construction measures and technical measures, reducing the green building incremental cost. And if feasibility studies are carried out later, there will be an increase of green building incremental projects, especially in the process of operation and maintenance, when the projects fail to reach the green building technology standards, there will be more additional technology and equipment, implementing green buildings' green function, leading to an increase of the incremental cost[4].

\section{QUANTIZATION OF GREEN BUILDING INCREMENTAL COST IN WHOLE LIFE}

Cost of construction life cycle include all the costs occurred in Whole life cycle[5]. And green building life cycle is divided into design of decision-making stage, construction stage and operation and maintenance stage,and scrap demolition stage, so the incremental cost will be identified and quantified from the whole life cycle. 


\section{The incremental cost during decision designing phase}

The incremental cost of green building decision designing stage, including not only the pre-project $\cos \mathrm{C}_{11}$ of the project feasibility study related to green buildings projects in early period, without considering the cost of land, energy, etc. The incremental cost also include the consulting and certificating cost of construction project, etc, certificating cost is $\mathrm{C}_{21}$. So the the incremental cost of $\mathrm{C}_{1}$ in designing phase is impressed as: $\mathrm{C}_{1}=\mathrm{C}_{11}+\mathrm{C}_{12}$.

\section{The incremental cost of construction stage}

Green building construction is a specific implementation stage, it is a process of project accomplishment,it is also a process that needs a lot of money.In this paper, we will study incremental cost of construction,concentrating on energy, land, water, material saving and indoor environment to identify and quantify the incremental cost of this stage [6]-[7].

(1) Incremental cost of land saving and outdoor environment

1) Incremental cost of permeable ground environment

The design of green buildings permeable ground outdoor, should not meet the soil permeability characteristics only, should also meet the daily needs of residents. Permeable ground can effectively reduce the urban heat island effect, improve the ability of surface water and groundwater collection, alleviate the pressure of the municipal drainage, incremental cost can be defined as $\mathrm{C}_{211}$.

2) Site improvement and land utilization

Choosing the field of green building project will certainly increase the project $\operatorname{cost} \mathrm{C}_{212}$. Reasonable planning of land,land saving, full development and utilization of underground spaces, improvement of the utilization ratio and effective combination of the green buildings' every functional range, then the cost is $\mathrm{C}_{213}$. So the incremental cost of Green building and the outdoor environment is expressed as: $\mathrm{C}_{21}=\mathrm{C}_{211}+\mathrm{C}_{212}+\mathrm{C}_{213}$.

(2) Incremental cost of the energy saving and using

1) Using the incremental cost of energy-using equipment

The energy-saving measures include some high efficiency equipment and systems such as energysaving lamps, air conditioners and elevators, incremental cost caused by these factors is $C_{221}$.

2) Incremental cost of peripheral structure

The energy saving measures of the outer envelope include the heat preservation and heat insulation of the roof, wall, windows, etc, which is the main part of the building energy saving design, the incremental cost is $\mathrm{C}_{222}$.

3) Incremental cost of lighting system

In building energy consumption, the energy-saving lamps, light source should be taken into consideration into the building lighting system, so the energy consumption of lighting system is relatively larger, the incremental cost in this stage is $\mathrm{C}_{223}$.

4) The incremental cost of renewable energy

In green building project, it is necessary to make full use of renewable energy, such as solar energy, geothermal energy, whose incremental cost is $\mathrm{C}_{224}$. Therefore, the total incremental cost caused by energy-saving projects can be defined as: $\mathrm{C}_{22}=\mathrm{C}_{221}+\mathrm{C}_{222}+\mathrm{C}_{223}+\mathrm{C}_{224}$.

(3) The incremental cost of water saving and using

1) The incremental cost of water-saving appliances and equipment

Green building in all regions should consider using water saving appliances and equipment, and water saving measures should be adjusted to local conditions, the incremental cost in this stage is $\mathrm{C}_{231}$. 


\section{2) Non-traditional water using}

Green buildings water saving projects make best use of non-traditional water sources, including water, rain and rivers. The use of non-traditional water sources, leading to an increasing fees on technology and safety measures, the incremental cost is $\mathrm{C}_{232}$.

3) The water-saving and irrigation technology

Water saving irrigation technology uses the intelligent facilities system to carry on the quantitative irrigation to the green space of green building project ., the use of these smart systems will produce certain incremental cost for $\mathrm{C}_{233}$. Therefore, the total incremental $\operatorname{cost} \mathrm{C}_{23}$ is expressed as: $\mathrm{C}_{23}=$ $\mathrm{C}_{231}+\mathrm{C}_{232}+\mathrm{C}_{233}$.

(4) Incremental cost of the material saving and material resources using

Green building materials in project is demonstrated by the selection of structure system, the choice of building materials, the savings of decoration and construction materials and the recycling of structural waste.

1) The application of green building materials

Green building materials is refers to the adoption of cleaner production technology, the use of fewer natural resources, the rational use of industrial and agricultural or urban solid waste production material. They can be reused to achieve the goal of sustainable development between architecture and environment. The material cost which is higher than that of the ordinary building is $\mathrm{C}_{241}$.

2) The processing cost of recycled building materials

In the construction process of Green building, we should try to choose old building materials and waste which we collect in sites or by other ways, they must be processed as building materials for the use of building products, $\mathrm{C}_{242}$ is the material cost of recycling process.

Hence, the incremental cost of materials saving project $C_{24}$ is expressed as: $C_{24}=C_{241}+C_{242}$.

(5) The indoor environment quality incremental cost

In the process of designing and implementing green building energy efficiency, we need to consider and assure wind environment, light environment, sound environment, thermal environment and environment quality inside the room, the $\operatorname{cost} \mathrm{C}_{251}$ results from the retaining structure of acoustic noise reduction and the cost $\mathrm{C}_{252}$ results from indoor air quality testing device and green equipment such as ventilatxion device, incremental $\operatorname{cost} \mathrm{C}_{25}$ of green indoor environment contains both of them, its computation formula is expressed as: $\mathrm{C}_{25}=\mathrm{C}_{251}+\mathrm{C}_{252}$.

To sum up, the green building construction phase of the incremental cost $\mathrm{C}_{2}$ is expressed as: $\mathrm{C}_{2}=\mathrm{C}_{21}+\mathrm{C}_{22}+$

$\mathrm{C}_{23}+\mathrm{C}_{24}+\mathrm{C}_{25}$.

\section{The incremental cost of operation and maintenance phase}

Green building operation and maintenance phase involves owners and property management company who are the main related subject of interests. They mainly focus on the operation of the green building environment, equipment maintenance and the save of energy consumption etc. The main work includes water saving, energy saving, material saving, and afforestation etc. They are also responsible for the treatment of emergency, the normal operation of the green building project area and beautiful environment.

\section{(1) Waste management}

The work of waste management includes the classification of garbage, the collection of garbage and the transportation of waste, fully abiding by the principles of resource and reduction, innocuity, the incremental cost resulting from waste management is $C_{31}$.

(2) The green management 
Green building project management mainly includes the management system of the green standard, the improvement of the late greening management, the park vegetation of normal care, the incremental cost resulting from the green management is $\mathrm{C}_{32}$.

(3) The intelligent management system

Green building intelligent management system is divided into three levels based on hardware configuration, technical level, different functional requirements and investment, the incremental cost of intelligent system is $\mathrm{C}_{33}$.

Therefore, the green building incremental cost of operation management are as follows: $\mathrm{C}_{3}=\mathrm{C}_{31}+$ $\mathrm{C}_{32}+\mathrm{C}_{33}$.

\section{The incremental cost of scrap removal stage}

Scrap removal stage for green building is the last stage of the whole life cycle cost management, the main work is the demolition of the green building entities, the recycle of green building materials, the dispose of the salvage value technology and equipment, scrap dismantled stage the incremental cost of $\mathrm{C}_{4}$ mainly includes the construction cost of $\mathrm{C}_{41}$ and recycling value $\mathrm{C}_{42}$ of building residue, and we should pay attention to the prevention and control of pollution and demolished which brings to the environment, the expression is expressed as: $\mathrm{C}_{4}=\mathrm{C}_{41}+\mathrm{C}_{42}$

In conclusion, the stages of whole life cycle of green building in the incremental cost LCC is expressed as: $\mathrm{LCC}=\mathrm{C}_{1}+\mathrm{C}_{2}+\mathrm{C}_{3}+\mathrm{C}_{4}$.

\section{CONCLUSION}

Development and promotion of green building is the necessary way of sustainable development of construction industry of our country, the incremental cost of green building, as an important factors hindering the development of the green building, it is necessary to carry out the comprehensive rational analysis and research. This article analyzes the factors affecting the incremental cost of green architecture from the perspective of the whole life cycle and from design, construction, operation and maintenance and scrap demolition, and then identify the phases of the incremental cost of quantitative, for green building reasonable positioning and providing a reference basis for decision-making, implements the green building whole life cycle stages of the incremental cost control and management effectively, promotes the sustainable development of green building.

\section{REFERENCE}

[1] Green Building Forum, Green building evaluation [M]. Beijing: China building industry press, 2007.

[2] Zuda Ye,The analysis about economic and technical cost benefit of green building [M]. Beijing:

China building industry press, 2013.

[3] Fang Wang,Influencing factors of incremental cost in green building[J]. Journal of Xinyang Normal University, 2011,4:558-561.

[4] Qian Li, Whole life cycle of green building assessment [D]. Dalian University of Technology, 2013,6:45-49.

[5] Shen Cao,Cong Dong.Life cycle cost benefit assessment for green building [J]. Journal of Tsinghua University,2012,6:843-847.

[6] Guangchen Liu. The study about incremental cost benefit of green building based on life-cycle theory [J]. science \& technology progress and policy, 2013,8:67-71.

[7] Jing Yan,Cost of green houses based on value engineering [J]. Building Energy Efficiency, 2013,9:23-25. 